\title{
Development of a cost calculation model and cost index for sheep production
}

\author{
Camila Raineri ${ }^{1}$, Thayla Sara Soares Stivari², Augusto Hauber Gameiro ${ }^{3}$
}

\author{
${ }^{1}$ Universidade Federal de Uberlândia, Faculdade de Medicina Veterinária, Uberlândia, MG, Brasil. \\ ${ }^{2}$ Universidade de São Paulo, Faculdade de Medicina Veterinária e Zootecnia, Programa de Pós-graduação em Produção e Nutrição Animal, \\ Pirassununga, SP, Brasil. \\ ${ }^{3}$ Universidade de São Paulo, Faculdade de Medicina Veterinária e Zootecnia, Departamento de Nutrição e Produção Animal, Pirassununga, SP, \\ Brasil.
}

ABSTRACT - The objective of this study was to develop a model for calculation and analysis of production costs of lamb and, from that, to elaborate a production cost index. Panel meetings were held in five regions of the state of São Paulo, Brazil, to define technical features of representative properties of lamb production, taken as a basis for the preparation of the cost calculation model. Then the model for production cost calculation was built. The third step consisted of monitoring prices of inputs used, calculating production costs along the studied period, and generating the cost index, by the Laspeyres model. Lastly, questionnaires were applied to sheep producers, to validate the cost index. The model for production cost calculation was planned to be of easy utilization by farmers, and simultaneously faithful to the theoretical principles. The adopted scheme of cost allocation followed the classification of "variable", "fixed operating", and "income of factors". We generated cost indexes for each of the five studied regions, which were then aggregated in a state index, by weighting regional indexes by flock size. More than $97 \%$ of the answers to the validation questionnaires were positive, so we considered that the index reached a high level of approval. The application of Economic Theory is essential for the development of cost calculation models. The developed model has potential to generate important information that can help producers to make decisions. It can work in many contexts, and it can even be adapted to other livestock species. The production cost index for lamb was approved and can collaborate with the organization of the sheep agroindustrial system.

Key Words: agribusiness, economy, economic indicator, farm management, lamb

\section{Introduction}

The process of modernization of agriculture has made it necessary for production factors to be exploited to their maximum, in order to achieve higher productivity and profitability rates. Accordingly, rural administration has become an alternative for the identification of the main bottlenecks in production systems. This should raise information capable of creating interventions in order to increase their efficiency (Viana and Silveira, 2008).

Primary production activity is the most vulnerable segment of agribusiness network due to its technology and management limitations. Since the producers cannot control the price of their product, they need to manage the variables under their control. Their economic outcome at a

Received June 27, 2015 and accepted August 9, 2015

Corresponding author: camila@paraisoovinos.com.br

http://dx.doi.org/10.1590/S1806-92902015001200005

Copyright (C) 2015 Sociedade Brasileira de Zootecnia. This is an Open Access article distributed under the terms of the Creative Commons Attribution License (http://creativecommons.org/licenses/by/4.0/), which permits unrestricted use, distribution, and reproduction in any medium, provided the original work is properly cited. competition-based market depends on the management of production costs and economies of scale (Reis et al., 2001).

According to Gameiro (2009), there is no "default protocol" for costing livestock: there are several manners to conceptualize costs concerning nature-related production systems. The usage of a simplified costing system for agribusiness companies makes it possible to follow the values of all operations within the property. This enables the discovery of causes of profit or loss (Callado, 2005).

The sheep industry has been a notable branch of Brazilian agribusiness since the early 2000s. It is referred to by producers as an activity of dynamic working capital invested with high profitability. However, sheep producers rarely hold financial control in their property or do not make use of all items comprised in the total cost of production. This unawareness represents a major chokepoint in the production chain. Thus, one important measure to be implemented is to enhance business management by knowing strategic information (Corah, 1995).

Carrer (2009) claims that monitoring the market in all its dimensions is fundamental for a better understanding of the dynamics of lamb production. Therefore, index 
numbers can be of great use. Index numbers are relative values, functions of prices and their respective amounts (Endo, 1986; Gameiro, 2003).

This research sought to develop a model for cost calculation and analysis for lamb production, and from that, to prepare a production cost index to follow its progress in the course of time.

\section{Material and Methods}

This study had no external funding sources; therefore, funders had no role in study design, data collection and analysis, decision for publishing, or preparation of the manuscript. The "Ethic Committee on the Use of Animals" of the School of Veterinary Medicine and Animal Science of Universidade de São Paulo certified that this research is in accordance with the ethical principles in animal research adopted by the institution. The process protocol number is 1993/2010, and it was approved in the meeting of November 11th, 2010. The Ethics Committee also presented no objections regarding the contributions of farmers and other participants during the various stages of this study.

This research was carried out in the state of São Paulo, Brazil, and its development consists of four steps. Firstly, panel meetings were held in order to identify and define the technical features of lamb production properties in five different areas of the state, upon which the building of the studied model was based. Then, the model for production cost calculation was defined, based on the study of Economic Theory. The third step consisted of monitoring the prices of inputs used in sheep raising and the calculation of production costs over the studied period, which allowed the preparation of cost indexes from the data and model generated by the previous procedures. The fourth and last step was the distribution of questionnaires among breeders and experts of the sector, aiming at validating the proposed cost index.

Productive features are somewhat heterogeneous for sheep raising properties in Brazil, especially concerning physical space, flock size, production system, mechanization rate, coexisting activities within the property, and management method. To address this subject, while bringing the analysis close to reality, there is a need to determine properties that satisfactorily represent those pre-existing in the state, called representative properties.

To this end, the panel meeting method was employed (Almeida, 2010; CONAB, 2010; Plaxico and Tweeten, 1963; Richardson et al., 2007; Vereijken, 1999). The panel consists of a meeting between the researcher and a group of producers and technicians of the respective area. The members of this meeting discuss together, and seek to design a representative production system of a given location. During the discussions, the group fills a previously organized spreadsheet, which should represent a typical situation of that area (Ferreira Filho et al., 2009). The technical and economic data used to describe the representative property are not raised individually or from statistical averages: they must be agreed on at a panel meeting. This made it possible to delineate one property representing each area of the state of São Paulo, Brazil, elected for the research, by means of the local experience of the producers. The study comprehended the regions of São José do Rio Preto, Bauru, Araçatuba, Campinas, and Piracicaba. All participants were informed about the objectives of the panel meetings, and were aware that the results would be utilized for educational and scientific purposes. Therefore, their option for participating in the study would implicate consent for utilizing the generated data.

The aspects approached on the panels correspond to six groups of characteristics, as follows: i) profile of the property and the manpower (total area of the property, area assigned for sheep production, period for which the activity has been conducted, amount of hours reserved for administration of the activity, amount of employees and time reserved for the sheep routine, existence or absence of technical assistance), ii) flock (number of ewes and rams, outcome rate, sheep breeds), iii) handling (stages of the production cycle performed, farming system, feed used, health management, weaning method, breeding system), iv) facilities and equipment, $v$ ) feed production (characteristics and handling of pastures, forage sources in dry period, origin of concentrates), and vi) animal-productivity indicators.

The scheme of cost allocation was based on the Economic Theory and different methods widely used in agriculture, which underwent adaptations for use in lamb production. The objective was to facilitate the practical use of the model, following a logic that is easily understandable and adoptable by farmers, while also meeting the theoretical precepts. Thus, in economic terms, the cost components were grouped into the following categories: variable costs, fixed operating costs, and total cost.

Into variable costs are grouped all components present in the process as productive activity develops, i.e., those that only apply if production occurs, and are directly related to the amount of livestock produced and the flock size. In this context, such items were feeding costs, medicines, taxes, and variable charges (such as the tax on movement of 
goods and services, - ICMS - and waybills for livestock - GTA).

The fixed operating costs include all expenses borne in upon the producer, regardless of the production volume, such as manpower and depreciation. The fixed operating cost is composed of all variable cost items and the portion of fixed costs directly associated with the implementation of the activity. Fixed cost items were considered those not directly related to the amount of lambs or flock size, such as: manpower, energy and fuel, depreciation, upkeep and maintenance, and taxes and fixed charges (such as rural land tax - ITR - and trade union contribution).

The fixed operating cost differs from the total cost only by not including the income of the factors, here considered as expected return on capital and land (Matsunaga et al., 1976). Total production cost comprises the operating cost plus the remuneration associated with the factors of production (CONAB, 2010). The total cost was obtained by summing the variable costs, fixed operating costs, and income of the factors, and subtracting the revenue from the sale of ewes culled from the flock. Thus, it represents solely the cost of lamb produced.

The criterion adopted for apportioning the costs shared between sheep production and other activities inside the property, such as machinery, manpower, electricity, and fuel is hours of use (Silva et al., 2008). Given the highly frequent coexistence of lamb production and other forms of agricultural exploitation, a correct apportionment is both critical for the accurate cost calculation of the sheep production and a challenge.

The sheep costs were prorated among all lambs (males and females) completed within one year. Thus, ewe lambs intended for replacement or for sale at an age higher than that of the lambs had their expenses computed only up to the time when the others were slaughtered.

As for production inputs and feed for the flock, only the amounts actually consumed by productive activities were considered. Thus, for calculation purposes, no stocks of input and/or feed were taken into account (Silva et al., 2008).

The input bundles, as well as their amounts, were established on the panels. The price surveys were drawn up monthly, between July and September 2012 for each area, via monthly communication by telephone with two informants for each input, such as agricultural resellers, farm machinery dealers, farmers, cooperatives, and other business establishments of each region where sheep breeders usually purchase their goods (CEPEA and CNA, 2003). Thus, the prices refer to the average prices paid by sheep producers at these points of sale, for cash payment. All values are expressed in Reais (R\$). According to the average exchange rate for the year 2012, R\$ 1.00 equals US\$ 0.5115 .

During the panels, participants had difficulties in understanding the concept of income of the factors, which contributed to the option of discussing it as a separate item, as adopted by Matsunaga et al. (1976) (Table 1). Such separation was also important to show that those costs may or may not represent an outlay, as the capital invested in sheep can be either private or funded. In the case of funded capital, compensation from its use represents an expense (payment of the funding), which does not occur if the capital is private. In this situation, such compensation represents a cost for the sheep production, but an income for the producer. A clear understanding of these concepts is essential for the accurate interpretation of the actual production cost and profitability.

Table 1 - Scheme adopted for allocation of production costs

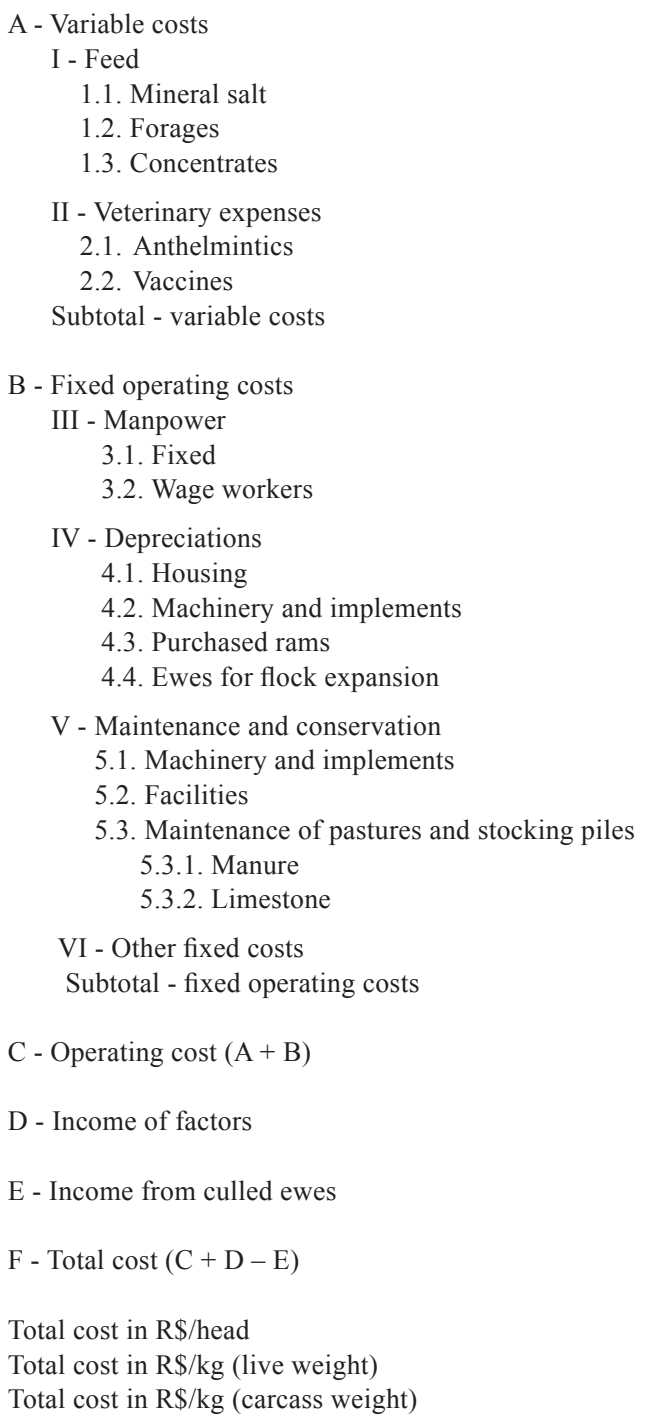

Source: data from the research. 
We chose to keep fixed technical indicators, inputs composing the bundles of each area, and their amounts throughout the study period. The seasonality of input use was handled as follows: the bundle of products was developed for the period of one year, in such a fashion that it could reflect the different items (services, feed, medicines, and others) employed in different seasons. So, the total costs calculated every month represent the cost of a full year, with updated prices for that month. The pricing of all products in the bundle of each region was determined monthly, on the last week of every month. Therefore, index variation reflects the impact on production cost of the variation of nominal prices of different inputs used in lamb production, in relation to the previous month. Occasionally, a periodical review of the technical indicators should be proposed, because sheep production is an increasing activity in terms of technology and market (CEPEA and CNA, 2003).

The method used to obtain the cost index was the Laspeyres index (Fisher, 1927; Gameiro and Caixeta Filho, 2010), which adopts a fixed weight basis (values for the base month) and considers the evolution of prices from one period to the other, by using Equation (1). The base month for the index was July 2012.

The cost index was first calculated individually for each of the five regions studied. Then, regional indexes were aggregated into a cost index for the state of São Paulo, by weighing the monthly costs of all five regions. The weighing basis was the number of sheep in each region estimated by the Instituto Brasileiro de Geografia e Estatística (IBGE, 2011).

With the purpose of verifying the adequacy of the index and validating it as a tool for the sheep industry, a questionnaire was prepared (Marconi and Lakatos, 1999) concerning the importance of the index, its reliability on depicting the behavior of the costs, and the interest of members of the chain in receiving regular updates.

This questionnaire was delivered to the participants at the "1st Field Day of LAE: Practical Management Tools in Sheep Industry", held on September 22, 2012. The event was promoted by the Laboratory of Socioeconomic Analyses and Animal Science (LAE) and designed to address topics of interest for sheep breeders, as manifestations expressed by the panelists suggest, being able to attract an audience capable of evaluating and validating the index.

Answering the questionnaires was not mandatory, and the participants were aware that the obtained answers would be utilized to evaluate and validate the research, and that the data collected could be published in scientific journals.
The participants who consented to cooperate returned the completed questionnaires at the end of the event.

\section{Results}

The costs were allocated into "variable", "fixed operating", and "income of factors" (Table 1). The model developed (Tables 2 and 3) was used to generate a spreadsheet for costs of lamb production.

The costs of all inputs allocated as variable costs (food, vaccines, and anthelmintics) were calculated following Equations (2) and (3).

In the proposed model, the price of one kilogram of pasture depends on the area used for grazing and the amount of grass consumed. Thus, although pasture is also an item of feed, and therefore a variable cost, its price is given by a logic that differs from the prices of other items in the same group. The price of pasture, to be inserted into Equation (2) in order to provide its cost, is calculated from Equation (4). For pastures, the price was calculated based on the opportunity cost of land lease in the region. Thus, the value of the pasture reflects the stocking rate utilized.

To calculate the cost of veterinary inputs, the same system as for the other variable cost items is adopted, by using Equations (2) and (3).

The costs computed in this category correspond to the use of drugs of controllable frequency in the flock (Table 4). On the panels it was found that the only items of this type employed in the representative properties are vaccines and anthelmintics.

The manpower cost was calculated according to Equations (5) and (6), and was allocated as a fixed cost.

The salaries surveyed on panels for registered employees and wage workers in each region were informed by local breeders, and their value includes social charges. The sheep industry employee shares his or her time with other activities within the representative property in all regions studied. To enable the apportionment of this cost, the amount of hours worked by the handler and the occasional wage worker(s) in each region was presented on the panels (Table 5). Both the duration of work shifts and the number of working days per year are related to the type of farming system adopted and work efficiency, among other factors.

Depreciation corresponds to the necessary financial reserves so that a similar asset can be acquired as its life cycle comes to an end due from wearing out or normal obsolescence (Marion, 2007). To calculate depreciation, the linear method was used (Cinquini Filho et al., 2011; Marion, 2007; Santos et al., 2009), as in Equations (7), (8), (9), and (10). 
Table 2 - Equations elaborated to compose the cost calculation model

\begin{tabular}{|c|c|}
\hline Equation & $\begin{array}{c}\text { Equation } \\
\text { number }\end{array}$ \\
\hline$I C P C_{r t}=\frac{C T_{r t}}{C T_{r 0}}$ & (1) \\
\hline$C I_{\text {iart }}=Q I_{i a r} P I_{i r t}$ & (2) \\
\hline$Q I_{i a r}=\left(q u_{i a r} u_{i a r}\right) N_{a r}$ & (3) \\
\hline$P I_{\bar{i} r t}=\left(\frac{\mathrm{ap}_{\mathrm{rt}} \mathrm{PA}_{\mathrm{rt}}}{\sum_{a} Q I_{\overline{i a r}}}\right)$ & (4) \\
\hline$C H_{h r t}=Q H_{h r} P H_{h r t}$ & (5) \\
\hline$Q H_{h r}=t u_{h r} v_{h r}$ & (6) \\
\hline$C D_{c r t}=\left(\frac{Q C_{c r t}-Q D_{c r t}}{v u_{c r}}\right) t a l_{c r}$ & (7) \\
\hline$Q C_{c r t}=q c_{c r t} P C_{c r t}$ & (8) \\
\hline$Q D_{c r t}=Q C_{c r t} t a d_{c r}$ & (9) \\
\hline$C D_{c r t}=\left[\frac{\left(1-t a d_{c r}\right) Q C_{c r t}}{v u_{c r}}\right] t a l_{c r}$ & (10) \\
\hline$P C_{\bar{c} r t}=\left(\frac{\mathrm{cub}_{\mathrm{t}}}{2}\right)$ & (11) \\
\hline$C M_{c r t}=\left(\frac{Q C_{c r t}}{v u_{c r}}\right) t a m_{c r}$ & (12) \\
\hline$C P_{m r t}=Q D_{m r} P D_{r t}$ & (13) \\
\hline$Q D_{m r}=p t_{m} r e_{m} h m_{m r} a p_{m r} n a_{m r}$ & (14) \\
\hline$C O_{o r t}=Q O_{o r} P O_{o r t}$ & (15) \\
\hline$R C I_{r t}=\operatorname{trc} c_{r t} \sum_{c} Q C_{c r t}$ & (16) \\
\hline$R C G_{r t}=\operatorname{trg}_{r t}\left(\sum_{i} \sum_{a} Q I_{i a r} P I_{i r t}+\sum_{m} Q D_{m r} P D_{r t}+\sum_{\bar{o}} Q O_{\bar{o} r} P O_{\overline{o r r t}}\right)$ & (17) \\
\hline$R C E_{r t}=a r_{r t} P A_{r t}$ & (18) \\
\hline$C V_{r t}=\sum_{i} \sum_{a} C I_{i a r t}$ & (19) \\
\hline$C F_{r t}=\sum_{h} C H_{h r t}+\sum_{c}\left(C D_{c r t}+C M_{c r t}\right)+\sum_{m} C P_{m r t}+\sum_{o} C O_{o r t}$ & (20) \\
\hline$C O T_{r t}=C V_{r t}+C F_{r t}$ & (21) \\
\hline$R C T_{r t}=R C I_{r t}+R C G_{r t}+R C E_{r t}$ & $(22)$ \\
\hline$C T_{r t}=C O T_{r t}+R C T_{r t}$ & (23) \\
\hline$Q N C_{r}=\delta_{r} \beta_{r} \varepsilon_{r}\left(12 \gamma_{r}{ }^{-1}\right) Q N O_{r}$ & (24) \\
\hline$Q P V_{r}=Q N C_{r} \eta_{r}$ & (25) \\
\hline$Q P C_{r}=Q P V_{r} \theta_{r}$ & (26) \\
\hline$Q N D_{r}=\alpha_{r} Q N O_{r}$ & $(27)$ \\
\hline$Q P D_{r}=Q N D_{r} \lambda_{r}$ & (28) \\
\hline$R O D_{r t}=Q P D_{r} P C_{\bar{c} r t}$ & (29) \\
\hline$C O U_{r t}=\frac{C O T_{r t}}{Q P V_{r}}$ & (30) \\
\hline$C T U_{r t}=\frac{C T_{r t}}{Q P V_{r}}$ & (31) \\
\hline
\end{tabular}

Source: data from the research.
In the isolated case of the facilities (housing), its value $\left(P C_{c r t}\right)$ is given by Equation (11). For all the other capital goods, it corresponds to its market price.

For machinery and equipment, the initial values used were those of the market, obtained from specialized dealers in the respective regions. Their residual values were set at $20 \%$ of initial values $\left(\operatorname{tad}_{c r}\right)$.

It was established that tractors were purchased used, and other machines (carts, stationary choppers, forage shredders) were purchased new. The life cycles considered were those indicated by the manufacturer of each device (Table 6).

As previously mentioned, the apportionment of costs between sheep industry and other activities within the property was based on the time of use of the good or service. Thus, the amount of working hours of machines and equipment was established on the panels for every representative property (Table 7 ).

The formula used to calculate the maintenance cost of facilities and equipment is Equation (12).

The maintenance of facilities (housing) and equipment (tractors, carts, forage shredders, and choppers) was calculated based on the fee $\left(\operatorname{tam}_{c r}\right)$ of $30 \%$ of the initial value of the asset, during its entire lifetime (AMPA and CEPEA, 2002).

The maintenance costs of pastures were calculated from necessary agricultural operations. The cost of fuel (diesel oil), maintenance of pastures, or any other mechanized operation is given by Equations (13) and (14).

As suggested by AMPA and CEPEA (2002), the fuel consumption $\left(Q D_{m r}\right)$ is estimated by multiplying the power of the tractor $\left(p t_{m}\right)$ by the factor $0.12\left(r e_{m}\right)$, resulting in the value in liters for one working hour. According to these authors, the yield for the distribution of manure or fertilizer is three hectares per hour $\left(h m_{m r}\right)$ for tractors with 65 horsepower (those utilized in the representative properties, according to data from the panels).

The subtopic "other fixed costs" refers to the fuel used in operations not related to the conservation of pastures and forages, electrical energy, and taxes and fixed charges. Therefore, diesel is used in activities such as harvest (where this operation is performed mechanically) and transport of bulky products.

Electrical energy includes a portion of KWh used to maintain the house(s) of employee(s) somehow involved with the sheep industry, to activate the electric forage chopper (in the areas in which this operation is performed), to maintain lamps and other equipment used for the lamb production. Since it is relatively complex to measure accurately the amount of energy spent on each item of 
Table 3 - Acronyms and definitions

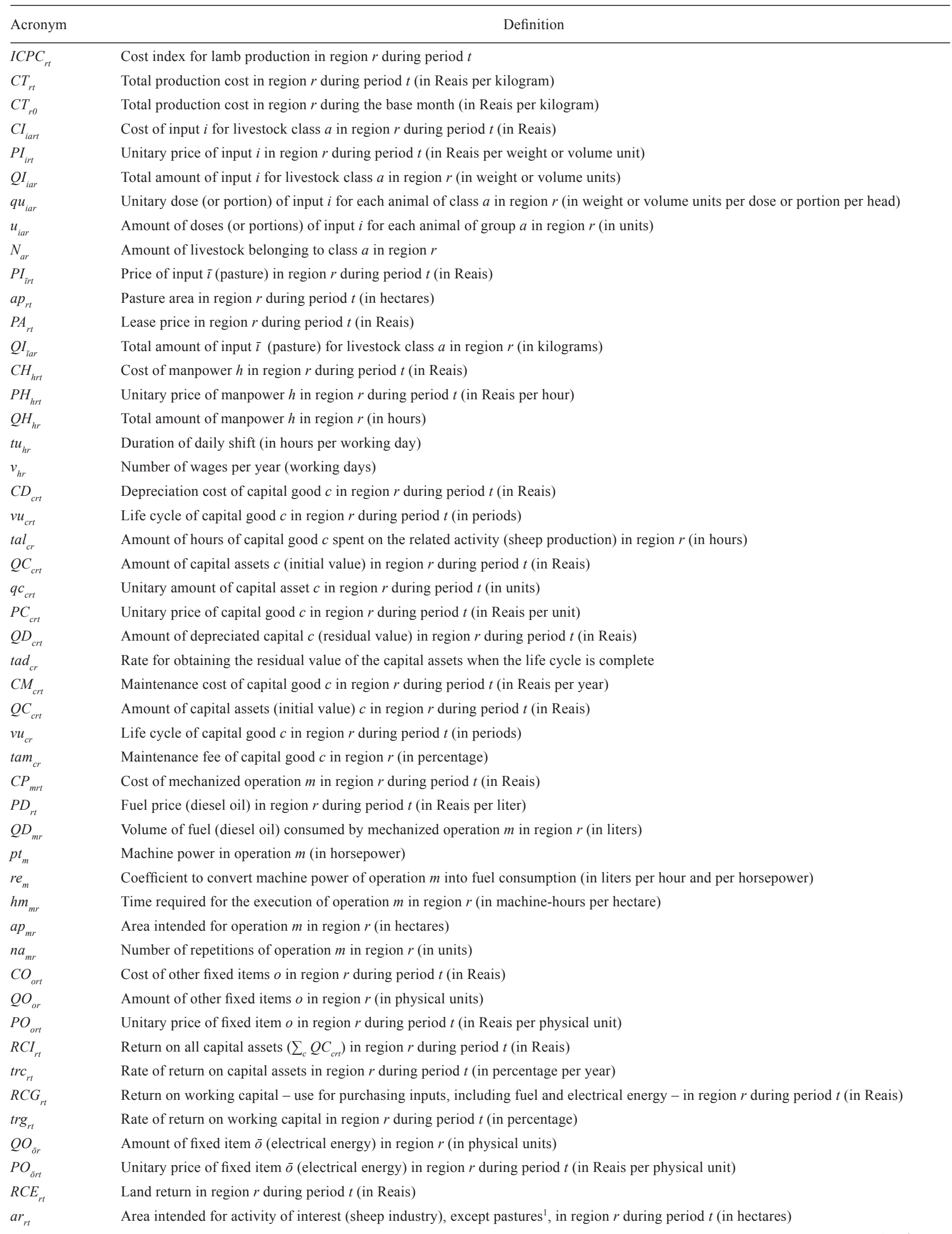


Table 3 (Continued)

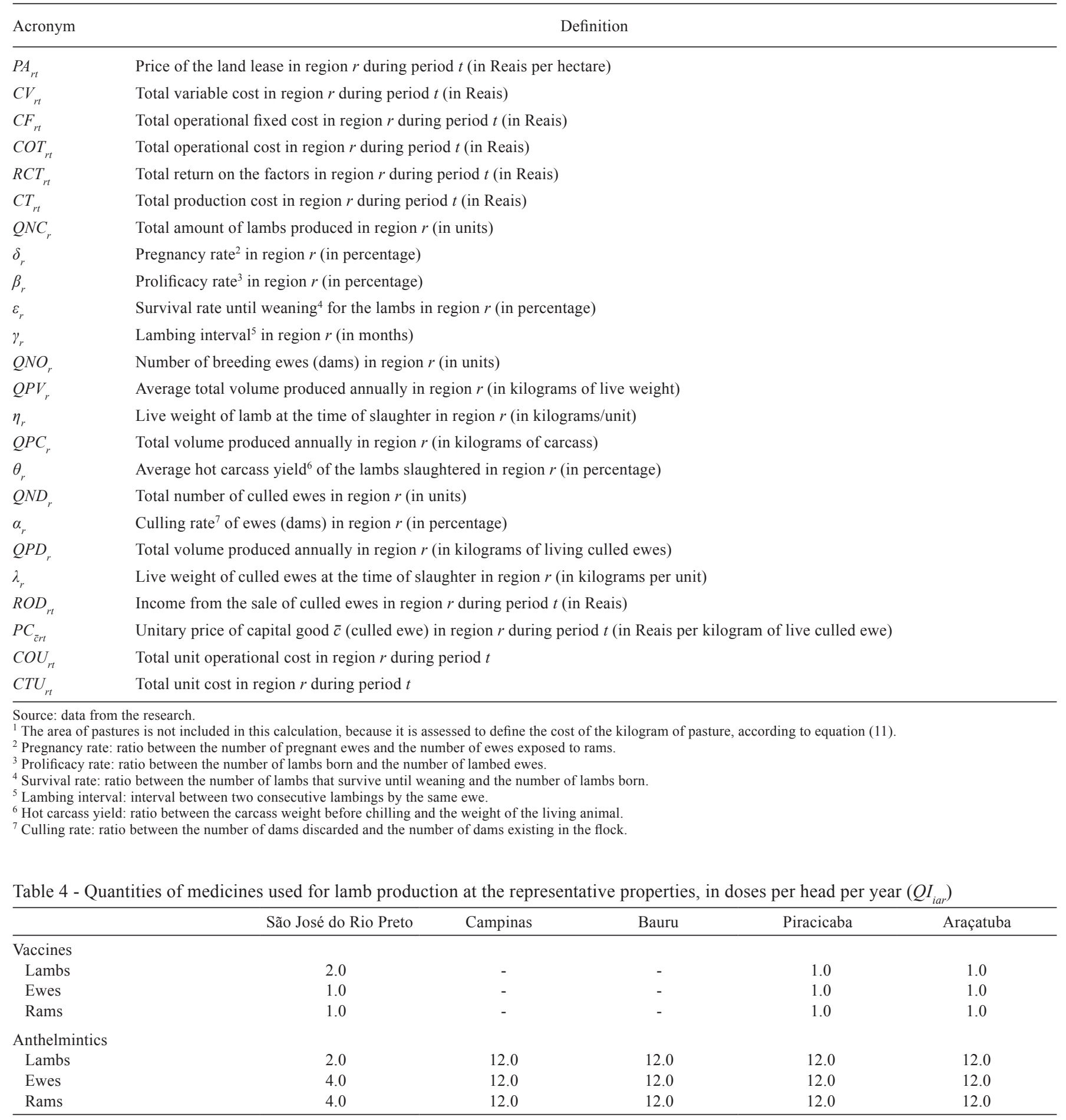

Source: data from the research.

Table 5 - Time spent by employees on sheep industry at the representative properties

\begin{tabular}{|c|c|c|c|c|c|}
\hline & São José do Rio Preto & Campinas & Bauru & Piracicaba & Araçatuba \\
\hline \multicolumn{6}{|l|}{ Registered employee } \\
\hline Daily working hours $\left(t u_{h r}\right)$ & 4.0 & 4.0 & 6.0 & 2.5 & 4.0 \\
\hline Annual working days $\left(v_{h r}\right)$ & 264.0 & 365.0 & 264.0 & 264.0 & 264.0 \\
\hline \multicolumn{6}{|l|}{ Wage worker } \\
\hline Daily working hours $\left(t u_{h r}\right)$ & 8.0 & - & 8.0 & 5.3 & 4.0 \\
\hline Annual working days $\left(v_{h r}\right)$ & 120.0 & - & 12.0 & 8.5 & 60.0 \\
\hline
\end{tabular}

Source: data from the research. 
Table 6 - Lifetime of facilities and equipment $\left(v u_{c r}\right)$

\begin{tabular}{lc}
\hline Item & Lifetime \\
\hline Housing & 20 years \\
Tractors with 65 or $75 \mathrm{hp}$ & $12,000 \mathrm{~h}$ \\
Carts with 2 or 4 wheels & $4,000 \mathrm{~h}$ \\
Forage shredder & $500 \mathrm{~h}$ \\
Stationary forage chopper & $7,500 \mathrm{~h}$ \\
\hline
\end{tabular}

Source: Secretaria da Receita Federal (1999).

the property, the amount of power associated with each agricultural activity is typically estimated by allocating the total invoice value among the cultures grown on the farm. It is important to highlight that the energy used for services not related to these activities (for example, gardening and owner's house maintenance) must not be considered for the assessment.

The Rural Land Tax (ITR) and the so-called "incidental expenses" and "administrative expenses" should also be allocated in this item in production cost calculation, but were excluded for the purposes of this research.

The cost of those other fixed items was calculated by utilizing Equation (15).

The income of the factors, in the proposed model, is the return from the use of capital. To calculate it, an interest rate is required to remunerate the working capital, the capital invested in physical assets, and land use (Lopes and Carvalho, 2002).

The return on capital assets was calculated according to Equation (16). The return on capital assets by the producer represents the portion calculated on the value of the asset purchased and used in production, and included in the fixed production cost (CONAB, 2010), such as facilities, equipment and breeding rams.

For the typical properties, with own capital goods, the rate levied $\left(t r c_{r t}\right)$ on the capital assets for calculating the income of factors was the benchmark Selic base interest rate. In the cases of investment with credit, the interest rate of the respective funding applied. This occurred in the representative property of Araçatuba, in which we invested by using the line of credit for sheep industry by Fund for
Expansion of Agribusiness in São Paulo (FEAP). The rate of interest of this loan was applied: $3 \%$ per year.

The return on working capital corresponds to the capital used for costing the livestock, i.e. expended on feed, veterinary inputs, diesel oil, and electrical energy. The return on working capital was calculated following Equation (17).

The rate $\left(\operatorname{trg}_{r t}\right)$ levied on the working capital for the calculation of the income of factors was the Selic rate, for a one-year period.

The method used to remunerate land use was its relation to the lease in the region where the property is located. Lopes and Carvalho (2002) claim that this criterion is widely used for the compensation of the factor of production land. Thus, land return is given by Equation (18).

Total variable cost was calculated by using Equation (19); total fixed operating cost was given by Equation (20); total operating cost, by Equation (21); total return on production factors, by Equation (22); and total cost was calculated, by Equation (23).

The amount of lambs produced is given by Equation (24). To obtain the production in kilograms of live weight, Equation (25) is utilized, and the production in kilograms of lamb carcass is calculated by Equation (26).

In relation to culled ewes, Equation (27) calculates the total number of these animals. To obtain the production in kilograms of live weight, Equation (28) is utilized, and the income of culled ewes is given by Equation (29).

The unit cost represents the production cost of one kilogram of living lamb. Total unit operating cost is given by Equation (30), while total unit cost is obtained by Equation (31).

From the monthly costs calculated for each region and applying formula (1), the regional production cost indexes for lamb were prepared (Table 8).

Regarding the Production Cost Index and weighted aggregate state costs and the regional data used for its calculation (Table 9), the weighting factor used for each region was the proportion of its flock in relation to the total flocks of all five regions.

Table 7 - Operating time of machinery and equipment for sheep industry in the representative properties, in daily hours $\left(t_{a l}\right)_{c r}$

\begin{tabular}{lccccc}
\hline & São José do Rio Preto & Campinas & Bauru & Piracicaba & Araçatuba \\
\hline Tractor with 75 hp & 0.5 & - & - & 0.5 & - \\
Tractor with 65 hp & - & 0.5 & 0.5 & - & - \\
Cart with 4 wheels & 0.5 & 0.5 & 0.5 & 0.5 & - \\
Cart with 2 wheels & - & - & - & - & - \\
Forage shredder & 0.5 & - & 0.5 & 0.5 & 0.5 \\
Stationary forage chopper & - & &
\end{tabular}

Source: data from the research 
The "1st Field Day of LAE: Practical Management Tools in Sheep Industry and release of the Production Cost Index for Lamb of São Paulo" was held on September 22, 2012. The event took place at the Department of Animal Production and Nutrition, at the School of Veterinary Medicine and Animal Science of Universidade de São Paulo, in the city of Pirassununga, São Paulo, Brazil. The agenda included lectures and practical classes on procedures and tools that aim to provide subsidies to the farmer, to help him or her make decisions more consciously, in different aspects of the activity. The event was widely publicized and mainly intended for sheep producers and experts working in the sector. Electronic and printed posters were sent to the regional divisions of the agricultural extension agencies of the State, the Houses of Agriculture of municipalities in the region of Pirassununga, agricultural dealers, and other establishments visited by breeders. The event was also publicized by the media specialized in sheep industry, such as printed magazines, web portals, mailings from breeders, and sheep breeding associations.
A total of 64 guests were received at the event, including 21 undergraduate and graduate students of Veterinary Medicine and Animal Science, 21 sheep producers, and 22 professionals working in the sector (farm employees, veterinarians, agronomists, and animal scientists). Interestingly enough, some of the sheep breeders present had also participated in panels; and initially there had been 60 places available.

At the time of enrollment, all participants were handed a folder containing the material for the event. Among other items, this material included a CD-ROM with the spreadsheet for calculation of lamb production costs developed in this research and a questionnaire for index validation

The last lecture of the day, named "Presentation and validation of the Production Cost Index for Lamb of São Paulo", was given by the author of the research. The main aspects of the work were displayed, such as its goals, the execution steps, and partial results of the behavior of cost index until then (as shown in Table 9). Also, the spreadsheet

Table 8 - Regional production cost index for lamb in the months of July (base month) - September, 2012

\begin{tabular}{lccc}
\hline Region & July $^{1}$ & August & September \\
\hline São José do Rio Preto & 100.0000 & 101.8858 & 100.8227 \\
Bauru & 100.0000 & 103.8317 & 102.7188 \\
Araçatuba & 100.0000 & 100.5651 & 100.9591 \\
Campinas & 100.0000 & 103.3447 & 104.0381 \\
Piracicaba & 100.0000 & 100.7114 & 99.7865 \\
\hline
\end{tabular}

Source: data from the research.

${ }^{1}$ Base month.

Table 9 - State production cost index for lamb in the months of July (base month) - September, 2012

\begin{tabular}{|c|c|c|c|c|c|}
\hline Mesoregion & Flock $^{1}$ & Weighting factor $^{2}$ & July $^{3}$ & August & September \\
\hline São José do Rio Preto & 78,201 & 0.34 & $\mathrm{R} \$ 7.23$ & $\mathrm{R} \$ 7.37$ & $\mathrm{R} \$ 7.29$ \\
\hline Bauru & 54,805 & 0.24 & $\mathrm{R} \$ 14.74$ & $\mathrm{R} \$ 15.31$ & $\mathrm{R} \$ 15.14$ \\
\hline Araçatuba & 43,438 & 0.19 & $\mathrm{R} \$ 30.82$ & $\mathrm{R} \$ 30.99$ & $\mathrm{R} \$ 31.11$ \\
\hline Campinas & 32,710 & 0.14 & $\mathrm{R} \$ 18.89$ & $\mathrm{R} \$ 19.52$ & $\mathrm{R} \$ 19.66$ \\
\hline Piracicaba & 19,144 & 0.08 & $\mathrm{R} \$ 32.47$ & $\mathrm{R} \$ 32.70$ & $\mathrm{R} \$ 32.40$ \\
\hline State of São Paulo & 228,298 & $100 \%$ & $\mathrm{R} \$ 17.31$ & $\mathrm{R} \$ 17.64$ & $\mathrm{R} \$ 17.58$ \\
\hline State Index & & & 100.0000 & 101.8874 & 101.5958 \\
\hline
\end{tabular}

Source: IBGE (2011) and data from the research.

$\mathrm{R} \$ 1.00=\mathrm{US} \$ 0.5115$.

${ }^{1}$ In heads.

${ }^{2}$ Proportion in relation to the total flocks of the state.

${ }^{3}$ Base month.

Table 10 - Evaluation of the production cost index for lambs by participants in 1st Field Day of LAE

\begin{tabular}{|c|c|c|c|c|}
\hline & Very high (\%) & High (\%) & Medium (\%) & Low $(\%)$ \\
\hline Importance of the production cost index for lamb & 60.87 & 39.13 & 0.00 & 0.00 \\
\hline Importance of access to cost calculation spreadsheet & 73.91 & 23.91 & 2.17 & 0.00 \\
\hline Adequacy of methodology of the index ${ }^{1}$ & 46.67 & 48.89 & 2.22 & 2.22 \\
\hline Interest in receiving evolution of the $\mathrm{ICPC}^{1}$ & 66.67 & 28.89 & 4.44 & 0.00 \\
\hline
\end{tabular}

${ }^{1}$ One participant did not answer the item. 
for calculation of production costs was demonstrated and explained. At the end of the presentation, the participants were invited to pick the questionnaires contained in the folders and to complete them. The speaker clarified that answering the questionnaires was not mandatory, and explained that the answers obtained would be utilized to evaluate and validate the research, and that the data collected could be published in scientific journals and used for educational purposes. It was emphasized that the participants who agreed to cooperate in this step should hand the completed questionnaires to any member of the organization staff at the end of the event, and that this would be considered as consent for data utilization. The questionnaires (Table 10) did not require participant identification, so anonymity was maintained.

Since over $62 \%$ of the answers were reviewed as "very high", and over $35 \%$ as "high", it was concluded that the Production Cost Index for Lamb of São Paulo reached a high level of approval.

Many participants expressed their expectations and other points of view regarding the Production Cost Index in the forms. Some of the aspects highlighted were its importance for the planning of production and as a benchmark for price negotiations with slaughterhouses, whereas others stressed the importance of knowing the costs for the professionalization of the activity and its economic viability. The fact that it is a free tool was also mentioned, and so was the importance of full disclosure of the index throughout the state.

\section{Discussion}

The scheme of cost allocation was guided by certain assumptions. Firstly, we chose to group them into "variable", "fixed operating", and "income of factors" because we believe this is more easily understood by the sheep producer. Also, it meets the principles of Economic Theory. Although the income of the factors is conceptually a fixed cost, it was separated to clarify the difference between the activity cost and the remuneration of the sheep producer by capital use. Manpower was designated as a fixed cost, because it is not considered to be directly associated with the amount of animals housed or produced. The number of employees at a production or the number of hours worked cannot be increased by adding one produced unit. This increase is related to several factors, such as the production system adopted, the necessary handlings, and substantial expansions in flock.

As recommended by Buchanan (1969), the concept of opportunity cost was applied to define the values of all cost items, including other roughage products (sugarcane and forages). Thus, the values adopted for these items correspond to their market price in their respective regions. Importantly, although there is no official marking of prices for harvested and chopped elephant grass, grown for silage, there is quite a notable market in the state, with several suppliers and buyers. Thus, the values assigned to roughage products refer to their purchase price at local market, even if the products have been grown inside the property.

The initial value adopted for the facilities (housing) was half of that indicated by CUB - Basic Unit Cost of Construction for the State of São Paulo (SINDUSCON-SP, 2012) - for the category of industrial buildings, and its residual value was equal to zero. The total CUB value was not used, because no facilities of the representative properties had been built for raising sheep, having been used for many years before for other purposes.

When adopting purchase prices for roughage products, these values include maintenance and conservation practices, here represented by the application of manure and the harvest of those roughage products. For this reason, there is no allocation of maintenance costs for the areas of production of such feeds in the group "maintenance of capital goods".

However, maintenance costs of pastures were considered fixed because, according to the panels, the area is fixed and does not depend on the amount of animals. The number of sheep in the area is related to the technology level adopted at the property, and translated by the stocking rate of the area.

The panelists were unanimous that it is not possible to estimate a monthly or annual amount spent on veterinary care or occasional use of other medicines, such as antibiotics, anti-inflammatory drugs, vitamins, and others. The reasons for this are the high variability of environmental conditions and general handling of the sheep, as well as shared use of drugs with other species present at the property, without an inventory control of the pharmacies. Moreover, it is common to use veterinary visits for other species to detect a certain condition among sheep, whereas a professional is rarely summoned only to meet sheep production.

The different quantities of drugs administered among the regions reflect the technological level of sheep production at the representative properties. The absence of vaccinations in Bauru and Campinas, for example, contributes to the high mortality rate of lambs in these regions. However, the high application of anthelmintics in all regions, except for São José do Rio Preto, suggests the lack of other worm control 
measures, such as animal selection and strategic prevention. Such a scenario predisposes parasites to rapid resistance due to the selection of most drug-resistant worms, and can inflict great harm on the activity. On the other hand, in the representative property of São José do Rio Preto, deworming is carried out rationally, only in animals affected by worms, less frequently, and along with the adoption of methods of supporting treatment and prevention.

According to Marion (2007), agricultural implements such as tractors and other equipment are not used continuously throughout the year because of off-seasons, idleness, and other factors. Thus, the author recommends that depreciation be appropriate as a result of the use in each culture. This makes it necessary to calculate depreciation per hour, by estimating a number of working hours per machine, rather than the number of years of life cycle. Being so, the daily operating time of each device for the sheep industry was listed for each region in panel meetings.

The depreciation (or depletion) of pastures and forages was not taken into consideration. Marion (2007) justifies that option for the following reasons: i) the use of perennial forage species, i.e., species that do not require periodic replenishment and ii) the adoption of maintenance practices, such as the employment of limestone and fertilizers, keeping these forages established and productive for an indefinite time.

As suggested by Gomes (1999) and Pirtouscheg (1999), depreciation of dams was not considered, as their replacement is derived from the flock itself. According to the authors, the cost of rearing ewe lambs to replace dams corresponds to the depreciation of these dams. However, breeding rams are not replaced by sheep born inside the flock, but acquired from third parties, so they had suffered depreciation and had a life cycle of two years and residual value equivalent to that obtained from the sale of the animal for slaughter.

In the calculation of production costs, a value must be registered and assigned for the compensation of the entrepreneur (Reis et al., 2001). However, because of the actual scenario of the sheep industry in São Paulo, this is a very subjective item. In field research, it was observed that the entrepreneur often has difficulty in assigning a value to his or her efforts because of the secondary character of sheep raising on farms. For this reason, the work of the owner was not included in the costs, as Matsunaga et al. (1976) recommends. Nevertheless, it is emphasized that the model allows the inclusion of such remuneration in manpower. To this end, an additional category $h$ would be considered, in Expressions (5) and (6).
The Rural Land Tax (ITR) and the so-called "incidental expenses" and "administrative expenses" were also excluded from the calculation of the production cost index at the representative properties, because these items would not meet the function intended by the research as a production cost index. Similarly to the compensation of the entrepreneur, these items are influenced by many aspects, which prevents them from being satisfactorily generalized. Furthermore, as observed on the panels, sheep raising is a secondary activity in the representative properties, and the apportionment of such costs would be complex. Thus, including such factors might cause distortions in the production cost index of lambs. Taxes on the sale of livestock were also not included in cost calculation, because they are deducted directly on lamb sale price. However, all these items should be controlled when analyzing the costs of a particular property.

The rate levied on the working capital for the calculation of the income of factors was the Selic rate, for a one-year period. The period considered was one year, although this is not necessarily the interval until the products (lambs) are marketed. We chose this period because of the difficulty in standardizing aspects of the lambing interval, especially at the properties in which no breeding season applies (as is the case with most representatives in this study), and in which the ewes present low reproductive seasonality, and thus the ability to cycle and reproduce throughout the year. When calculating the costs of production for a particular property, this aspect should be taken into account, and may be adjusted depending on the characteristics of the production system.

Data indicate an increase in the index in August and September compared to July for all regions, except for Piracicaba in September. The major cost items responsible for this behavior were the grains (corn and soybean), the land lease, and the benchmark Selic base interest rate. From September, prices of cereals used for concentrates began to decrease after a long period of increase. The sugar cane, which not only is fed to livestock in several regions as roughage, but also reckons the lease value, had a slight decrease in price per ton since July. However, the Selic interest rate, used as a basis for the income of factors, increased during the entire period studied. The production cost index for lamb decreased in the region of Piracicaba, due to a greater reduction in the lease value in relation to the other regions studied.

In spite of the validation, the cost calculation method and the Production Cost Index itself must be analyzed over time. In order to do this, the opinion and suggestions of the users of the spreadsheet and index are very important 
and provide subsidies for continuous adjustments and improvements.

\section{Conclusions}

The application of the basic concepts of Economic Theory to calculate the production costs, such as opportunity cost, is essential for the development of cost calculation models. It is necessary to compute all items in the calculation, unlike the frequently observed mistake of not including several cost groups in the analysis. These are peculiarities of the cost calculation model developed in this work, which shows clarity and versatility for use by farmers.

The calculation model developed allows the sheep producer to know precisely the production costs. Also, it can potentially generate important information that helps him or her make decisions, such as the composition of costs and indications of economic bottlenecks in production.

The Production Cost Index for Lamb can be seen as an important tool for the market and the agribusiness network, as it has the potential to collaborate with the organization of the sector, assisting in market transparency, marking of prices, and the reduction of information asymmetry.

Both the model and the index prepared are sufficiently complete and dense to be replicated in other regions, under different conditions, and even in other species.

\section{References}

Almeida, M. H. S. P. 2010. Análise econômico-ambiental da intensificação da pecuária de corte no Centro-Oeste brasileiro. Dissertation (M. Sc.). Universidade de São Paulo, Piracicaba.

AMPA - Associação Mato-grossense dos Produtores de Algodão and CEPEA - Centro de Estudos Avançados em Economia Aplicada. 2002. Guia de utilização do programa de cálculo do custo de produção do algodão no Mato Grosso. CEPEA, Piracicaba.

Buchanan, J. M. 1969. Cost and choice: an inquiry in economic theory. Liberty Fund Inc., Indianapolis.

Callado, A. A. C. 2005. Agronegócio. Atlas, São Paulo.

Carrer, C. C. 2009. A cadeia de negócios da ovinocultura de corte paulista: diagnóstico de pontos críticos e proposta de estruturação técnica e mercadológica. Lawbook, Pirassununga.

CEPEA - Centro de Estudos Avançados em Economia Aplicada and CNA - Confederação da Agricultura e Pecuária do Brasil. 2003. Metodologia do índice de preços dos insumos utilizados na produção pecuária brasileira. Available at: $<$ http://www.cepea. esalq.usp.br/boi/metodologiacna.pdf.> Accessed on: Nov. 23, 2009.

Cinquini Filho, J.; Moura, M. S.; Carreon, R. S. and Pirtouscheg, A. 2011. Desempenho econômico do sistema de produção de cria, recria e engorda em bovinos de corte da Fazenda Rosário, Ituiutaba-MG. Pubvet 5:9.

CONAB - Companhia Nacional de Abastecimento. 2010. Custos de produção agrícola: a metodologia da Conab. Conab, Brasília.
Corah, L. 1995. The history of IRM and SPA. Veterinary Clinics of North America: Food Animal Practice 11:191-198.

Endo, S. K. 1986. Números índices. Atual, São Paulo.

Ferreira Filho, J. B. S.; Alves, L. R. A. and Villar, P. M. 2009. Estudo da competitividade da produção de algodão entre Brasil e Estados Unidos - safra 2003/04. Revista de Economia e Sociologia Rural 47:59-88.

Fisher, I. 1927. The making of index numbers. Houghton Mifflin Company, Boston.

Gameiro, A. H. 2003. Índices de preço para o transporte de cargas: o caso da soja a granel. Thesis (Ph. D). Universidade de São Paulo, Piracicaba.

Gameiro, A. H. 2009. Análise econômica aplicada à zootecnia: avanços e desafios. p.9-32. In: Novos desafios da pesquisa em nutrição e produção animal. Santos, M. V.; Rennó, F. P.; Prada e Silva, L. F.; Albuquerque, R., eds. Ed. 5D, Pirassununga.

Gameiro, A. H. and Caixeta Filho, J. V. 2010. Índices de preço para o transporte de cargas: o caso da soja. Nova Economia 20:121-163.

Gomes, S. T. 1999. Cuidados no cálculo do custo de produção de leite. In: Anais do $1^{\circ}$ Seminário sobre Metodologias de Cálculo do Custo de Produção de Leite. ESALQ/USP, Piracicaba.

IBGE - Instituto Brasileiro de Geografia e Estatística. 2011. Pesquisa pecuária municipal. Available at: $<\mathrm{http} / /$ www.sidra.ibge.gov.br/ $\mathrm{bda} / \mathrm{acervo} / \mathrm{acervo} 2 \mathrm{asp} ? \mathrm{e}=\mathrm{v} \& \mathrm{p}=\mathrm{PP} \& \mathrm{z}=\mathrm{t} \& \mathrm{o}=24>$ Accessed on: Sept. 27, 2013.

Lopes, M. A. and Carvalho, F. C. 2002. Custo de produção do gado de corte. Boletim Agropecuário 47. UFLA, Lavras.

Marconi, M. D. A. and Lakatos, E. M. 1999. Técnicas de pesquisa: planejamento e execução de pesquisa, amostragens e técnicas de pesquisa, elaboração, análise e interpretação de dados. 4.ed. Atlas, São Paulo.

Marion, J. C. 2007. Contabilidade rural. 8.ed. Atlas, São Paulo.

Matsunaga, M.; Bemelmans, P. F.; Toledo, P. E. N.; Dulley, R. D.; Okawa, H. and Pedroso, I. A. 1976. Metodologia de custo de produção utilizada pelo IEA. Agricultura em São Paulo 23:123-139.

Pirtouscheg, A. 1999. Custos de produção na agropecuária e planejamento rural. Universidade Federal de Uberlândia, Uberlândia.

Plaxico, J. S. and Tweeten, L. G. 1963. Representative farms for policy and projection research. Journal of Farm Economics 45:1458-1465.

Reis, R. P.; Medeiros, A. L. and Monteiro, L. A. 2001. Custos de produção da atividade leiteira na região sul de Minas Gerais. Organizações Rurais e Agroindustriais 3:45-52.

Richardson, J. W.; Outlaw, J. L.; Knapek, G. M.; Raulston, J. M.; Herbst, B. K.; Fumasi, R. J.; Anderson, D. P.; Bryant, H. L.; Klose, S. L. and Zimmel, P. 2007. Representative farms economic outlook for the December 2007 FAPRI/AFPC baseline. Agricultural and Food Policy Center, Working Paper 07-3. Available at: $<$ http://purl.umn.edu/37977>. Accessed on: Sept. 27, 2013.

Santos, G. J.; Marion, J. C. and Segatti, S. 2009. Administração de custos na agropecuária. Atlas, São Paulo.

Secretaria da Receita Federal. 1999. Instrução Normativa SRF $n^{\circ}$ 130/1999. Dispõe sobre a vida útil e a taxa de depreciação dos bens que compõe o ativo imobilizado. Available at: $<$ http://www.receita. fazenda.gov.br/pessoajuridica/dipj/2005/pergresp2005/pr360a373.htm>. Accessed on: Nov. 18, 2015.

Silva, R. W. S. M.; Oliveira, J. C. P.; Eggleton, C. M. J.; Echevarria, F. and Pinheiro, A. C. 2008. Sistema de Criação de Bovinos de Leite para a Região Sudoeste do Rio Grande do Sul. (Sistema 
de Produção 3) Embrapa Pecuária Sul, Bagé. Available at: $<$ http://sistemasdeproducao.cnptia.embrapa.br/FontesHTML/ Leite/BovinoLeiteRegiaoSudoesteRioGrandeSul/index.htm.>. Accessed on: Oct. 2, 2013.

SINDUSCON-SP - Sindicato da Indústria da Construção Civil no Estado de São Paulo. 2012. Custo Unitário Básico da Construção Civil (CUB). Available at: <http://www.sindusconsp.com.br/msg2. asp?id=5374. $>$. Accessed on: Sep. 27, 2013.
Vereijken, P. 1999. Manual for Prototyping Integrated and Ecological Arable Farming Systems (I/EAFS) in Interaction with Pilot Farms. AB-DLO, Wageningen.

Viana, J. G. A. and Silveira, V. C. P. 2008. Custos de produção e indicadores de desempenho: metodologia aplicada a sistemas de produção de ovinos. Custos e Agronegócio on line 4:3. Available at: $<\mathrm{http}$ ://www.custoseagronegocioonline.com.br/numero3v4/custos \%20de\%20producao\%20ovinos.pdf $>$. Accessed on: Sept. 27, 2013. 